\title{
RECORDAÇÕES, DISPUTAS E ENFRENTAMENTOS ENTRE MEMÓRIAS: A PRESENÇA PORTUGUESA EM FOZ DO IGUAÇU
}

\author{
Samuel Cabanha \\ Secretaria Municipal de Assistência Social em Foz do Iguaçu (SMAS), Brasil \\ E-mail:samuelcabanha@globo.com \\ ORCID: https://orcid.org/0000-0003-3706-7762 \\ Samuel Klauck \\ Universidade Estadual do Oeste do Paraná (UNIOESTE), Brasil. \\ E-mail: samuelk98@msn.com \\ ORCID: https://orcid.org/0000-0003-4804-5286 \\ Data de recebimento: 01/10/2019 \\ Data de aprovação: 29/05/2020 \\ DOI: https://doi.org/10.30612/frh.v22i39.12576
}

\begin{abstract}
Resumo: Este artigo aborda alguns elementos da imigração portuguesa em Foz do Iguaçu no período de 1957 a 2016. Explora as memórias e as trajetórias de vivências de dois imigrantes portugueses nesta cidade, de modo a evidenciar como as memórias afloradas nas entrevistas narram o seu grupo de pertencimento. A metodologia adotada foi a pesquisa qualitativa, seguindo os pressupostos teórico-metodológicos da História Oral. O levantamento de dados se consistiu na pesquisa documental clássica, e em parte, no uso de fontes orais através de entrevistas e de fontes impressas. De forma sucinta, o arcabouço teórico gira em torno de discussões que envolvem os conceitos ligados à memória e à identidade, evidenciando como as memórias portuguesas afloradas nas entrevistas e nos afazeres do grupo atuam como marcadores identitários. Como resultado, o estudo (re)constrói alguns detalhes das trajetórias, do cotidiano, da vida material dos depoentes e do grupo de imigrantes portugueses em Foz do Iguaçu. Dessa forma, demonstra como a identificação do grupo se articulou de modo que edificaram para si um lugar de memória, "a Casa de Portugal", e deixa algumas migalhas que contam um pouco do vai e vem da comunidade portuguesa na cidade. A pesquisa sobre a comunidade portuguesa em Foz do Iguaçu impacta os estudos sobre multiculturalidade na região e serve de pano de fundo e abertura para estudos futuros.
\end{abstract}

Palavras-chaves: Memória. Identidade. Portugueses. Foz do Iguaçu.

\section{MEMORIES, DISPUTES, AND FACES BETWEEN MEMORIES: THE PORTUGUESE PRESENCE IN FOZ DO IGUAÇU}

\begin{abstract}
This article deals with some elements of Portuguese immigration in Foz do Iguaçu from 1957 to 2016. It explores the memories and travels of experiences of two Portuguese immigrants in Foz do Iguaçu, in order to show how the memories surfaced in the interview narrated to your sample group. The methodology adopted was the qualitative research, following theoretical-methodological assumptions of the Oral History, and the data collection
\end{abstract}


consisted of classic documentary research, and partial use of oral sources through interviews and printed sources. Briefly, the theory framework revolves around discussions that involve concepts related to memory, and identity, showing how Portuguese memories that surfaced in the interviews and in the group's activities act as identity markers. As a result, the study reconstructs some details of the travel, the daily life, the material life of the deponents and the group of Portuguese immigrants in Foz do Iguaçu. In this way, it demonstrates how the identity of the group was influential so that they built for themselves a place of memory "The House of Portugal", and leaves some crumbs that tell a little of the comings and goings of the Portuguese community in the city. Research on the Portuguese community in Foz do Iguaçu impacts the studies on multiculturalism in the region, and serves as a fundation and opening for future studies.

Keywords: Memory. Identity. Portuguese. Foz do Iguaçu.

\section{RECORDACIONES, DISPUTAS Y CONFRONTACIONES ENTRE MEMORIAS: LA PRESENCIA PORTUGUESA EM FOZ DE IGUAZÚ}

Resumen: Este artículo analiza algunos elementos de la inmigración portuguesa en Foz de Iguazu desde 1957 hasta 2016. Explora los recuerdos y las trayectorias de vida de dos inmigrantes portugueses en esta ciudad, para mostrar cómo los recuerdos surgidos en las entrevistas narran su grupo de pertenencia. La metodología adoptada fue la investigación cualitativa, siguiendo los supuestos teórico-metodológicos de la historia oral. La recopilación de datos consistió en la investigación documental clásica y, en parte, en el uso de fuentes orales a través de entrevistas y fuentes impresas. Sucintamente, el marco teórico gira en torno a discusiones que involucran los conceptos relacionados con la memoria y la identidad, mostrando cómo surgieron los recuerdos portugueses en las entrevistas y como el recorrido del grupo actúa como un marcador de identidad. Como resultado, el estudio (re)construye algunos detalles de las trayectorias, la vida cotidiana, la vida material de los declarantes y del grupo de inmigrantes portugueses en Foz de Iguazú. Por lo tanto, demuestra cómo se articuló la identificación del grupo para que construyeran para sí mismos un lugar de memoria, la "Casa de Portugal", y deja algunas migajas que cuentan un poco sobre las idas y venidas de la comunidad portuguesa en la ciudad. La investigación sobre la comunidad portuguesa en Foz de Iguazú impacta los estudios sobre multiculturalismo en la región y sirve como fondo y apertura para futuros estudios.

Palabras clave: Memoria. Identidad. Portugueses. Foz de Iguazú.

\section{Introdução}

As análises que seguem são fruto da bricolagem e intertextualidade de uma dissertação de mestrado intitulada "Memórias que narram a cidade: a trajetória de dois imigrantes portugueses em Foz do Iguaçu", realizada no Programa de Pós-Graduação Stricto Sensu em Sociedade, Cultura e Fronteiras, na Universidade Estadual do Oeste do Paraná UNIOESTE, campus de Foz do Iguaçu. A partir desse trabalho, decidiu-se apresentar, em 
forma de artigo, algumas migalhas dessa experiência. Assim, o objetivo deste artigo é problematizar os processos de construção de identidades e enfatizar a(s) sociabilidade(s) do grupo de portugueses em Foz do Iguaçu por meio das disputas e enfrentamentos entre memórias através dos relatos de memórias de dois depoentes e de um processo judicial.

A coleta de dados ocorreu entre os anos de 2015 e 2017, na tentativa de buscar alguns elementos da imigração portuguesa em Foz do Iguaçu entre 1957 e 2016. Fundamentou-se na exploração de relatos de memórias contidos nas narrativas de dois interlocutores, sob os seguintes aspectos: 1) as narrativas como fruto da memória individual e coletiva que perpassam as vivências dos depoentes; e, 2) as memórias e as representações que narram o seu grupo de pertencimento. Balizado nesses dois aspectos, buscou-se (re)construir alguns detalhes das vivências e do cotidiano dos narradores, de modo a falar um pouco do grupo de imigrantes portugueses em Foz do Iguaçu e, por fim, destacar como esse grupo edificou para si um lugar de memória, qual seja, Associação Cultural Luso-Brasileira em Foz do Iguaçu, atualmente denominada como Casa de Portugal ${ }^{1}$. Esta última como resultado da necessidade dos imigrantes portugueses em possuir um lugar de referência como núcleo de sociabilidade, de pertencimento, de identificação, de preservação de memórias.

\section{A casa, a história oral e a memória}

Durante o tempo de elaboração da pesquisa não se pôde ter acesso ou, até mesmo, adentrar na Casa, pois ela figurava como objeto de disputa judicial com pedido de reintegração de posse, cuja disputa tem como cerne uma pequena faixa de terra. Esse fator merece ser destacado, pois o acesso aos espaços internos da Casa de Portugal, aos seus cômodos, aos seus acervos, com certeza, possibilitaria abrir portas e vertentes de análise. Ainda assim, este artigo retrata alguns aspectos da construção da Casa de Portugal, de sua missão e das memórias de seu entorno, fatos que puderam ser colhidos e analisados através dos relatos orais dos depoentes, dos documentos, imagens e do acesso ao processo judicial, que foi peça imprescindível para elaboração deste artigo.

\footnotetext{
${ }^{1}$ A Casa de Portugal tem por endereço a Avenida Portugal no 726, Bairro Polo Centro. No ato de sua fundação a Casa de Portugal tinha o nome de Associação Cultural Luso-Brasileira.
} 
Figura 01: Foto da fachada da Associação Cultural Luso-Brasileira de Foz do Iguaçu.

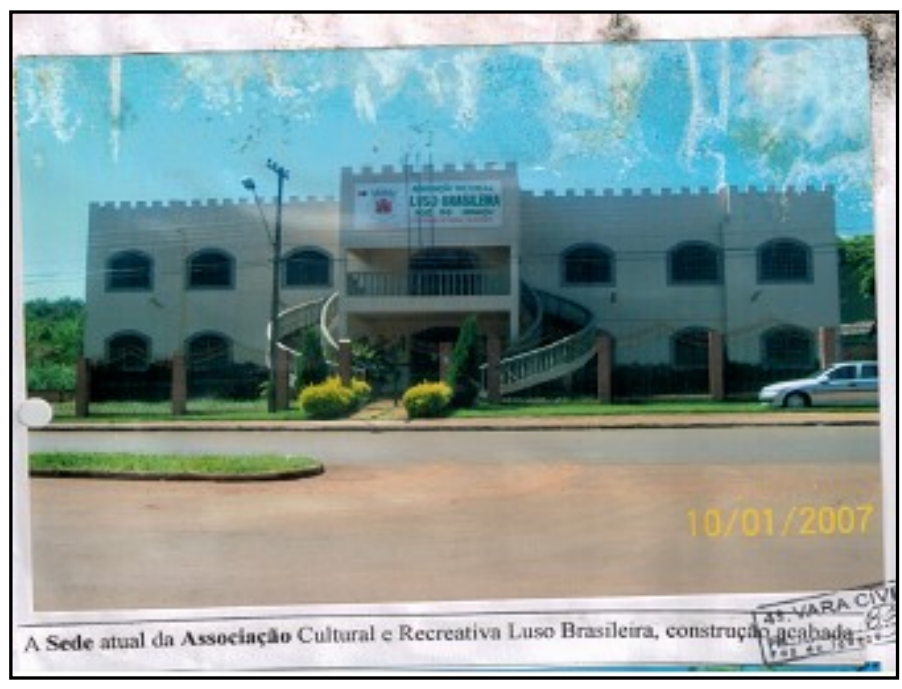

Fonte: (PARANÁ, 2007, Fls. 83)

Até a data de conclusão da escrita da dissertação o processo ainda tramitava na Justiça Estadual $^{2}$, tendo iniciado no ano de 2007. Cabe dizer que as informações relativas à Casa de Portugal foram encontradas no processo judicial e nas entrevistas, pois se visitou a casa poucas vezes, pois por estar fechada e seu acesso interditado, apenas contemplou-se sua estrutura e arquitetura pelo lado de fora. Para aguçar o imaginário do leitor, que apenas terá a casa apresentada através de algumas narrativas e imagens, é pertinente ressaltar que ao passar pelo lugar o transeunte percebe que a paisagem é afetada pela arquitetura da casa, a qual relembra e remete ao perfil de uma edificação de uma cidade medieval portuguesa, representando a imagem de um antigo castelo, conforme se observa na figura 1 (a seguir).

Exercitar a imaginação no leitor é importante porque se acredita que a Casa de Portugal produz um efeito que concatena reminiscência de "um lugar" e seu contexto simbólico. Assim, infere-se que ao recriar a imagem de um castelo, a comunidade portuguesa procura torná-la um monumento, pois segundo Le Goff (2013, p. 486) “o monumento é tudo aquilo que pode evocar o passado, perpetuar a recordação". Aqui sobressaem-se as dimensões simbólicas da Casa de Portugal, onde, fachada, insígnias e arquitetura proporcionam curiosidade e certo ar de mistério. Na imponente fachada da casa se destaca uma bandeira e um brasão com a inscrição "Casa de Portugal”.

\footnotetext{
${ }^{2}$ Processo Judicial registrado sob o número 0016158.78.2007.8.16.0030, na 4 a Vara Cível da Comarca de Foz do Iguaçu, onde figura como polo ativo a imobiliária Foz Nações e como polo passivo a Associação Cultural LusoBrasileira em Foz do Iguaçu, nome ainda utilizado pela Casa de Portugal quando deu início a ação judicial, no ano de 2007.
} 
Por sua vez, o processo judicial, que envolve a Casa de Portugal, só foi descoberto no transcurso da pesquisa. Em outro momento, a partir do contato com um representante do Consulado de Portugal em Foz do Iguaçu, revelou-se o primeiro depoente, cidadão de nacionalidade portuguesa, residente no Brasil desde o ano de 1952 e, radicado em Foz do Iguaçu desde o ano de 1959.

O contato e a aproximação com o primeiro depoente resultaram na indicação de outro cidadão português, radicado no município de Foz do Iguaçu desde o ano de 1957. Com a definição desses contatos, decidiu-se trabalhar com as memórias e vivências dos depoentes ${ }^{3}$, Manuel Alves Pereira Martins e João da Silva Lavado. Dessa forma, optou-se por uma pesquisa alicerçada nos pressupostos teórico-metodológicos da História Oral (HO). Quando se optou pela $\mathrm{HO}$, a convicção era que os narradores apresentariam "algo significativo e especial", não do ponto de vista da história convencional, mas da história de baixo, pois conforme pontua Bauer (2007), a necessária visão geral "de baixo”, a partir da experiência individual, só pode ser obtida com a ajuda da história oral (BAUER, 2007, p. 154). Dessa forma, era importante e necessário "descer" até o microcosmo dessa singularidade, como nos aponta Ginzburg (2006), quando diz que

\begin{abstract}
Alguns estudos biográficos mostraram que um indivíduo medíocre, destituído de interesse por si mesmo - justamente por isso representativo -, pode ser pesquisado como se fosse um microcosmo de um estrato social num determinado período histórico (GINZBURG, 2006, p. 20).
\end{abstract}

As entrevistas foram realizadas conforme um roteiro de específico de perguntas, seguindo a forma semiestruturada, porém sem se ater a um padrão muito rígido, deixando aos narradores foi dada a liberdade de falarem quando já se tinha alcançado alguns objetivos durante a entrevista. Elas trouxeram aspectos singulares de suas vidas, mas também do coletivo, como dados para interpretação e compreensão das representações e memórias portuguesas em Foz do Iguaçu.

Dos relatos orais e das vivências dos depoentes, extraiu-se dois fatos que foram explorados mais a fundo: a construção de uma identidade por meio dos relatos de memórias e da(s) sociabilidade(s) do grupo de portugueses e a edificação da Casa de Portugal. Isso

\footnotetext{
${ }^{3}$ A fim de organizar o trabalho e atender a necessidade da compreensão e a legibilidade de Termos de Consentimento Livre e Esclarecido (TCLE) dos participantes e, primando pela fidedignidade e qualidade das informações, os depoentes receberam uma via dos TCLE assinadas, conforme Parecer Consubstanciado do CEP (UNIOESTE) através do $n^{\circ} 1.741 .605$.
} 
sedimentou o alicerce das análises baseadas na dimensão simbólica das memórias e narrativas dos interlocutores.

\section{A(s) vivência(s) e a(s) memória(s) como "objeto" de análise}

A compreensão do conceito de memória, memória coletiva e identidade são cruciais para demonstrar como os conceitos são inextricáveis. Esse arcabouço teórico permite abordar as narrativas como um método eficaz e apto para evidenciar a comunidade portuguesa no município, para demonstrar como esse grupo se articulou através da associação e como ocupou e consolidou um espaço de visibilidade social, criando, para si, um lugar de memória: a Casa de Portugal. Essas memórias, como elo de contínua interpretação do passado, são a voz e a imagem do acontecido e, segundo Le Goff (2013, p. 387), “a memória, como propriedade de conservar certas informações, remete-nos, em primeiro lugar, a um conjunto de informações psíquicas, graças às quais o homem pode atualizar impressões ou informações passadas, ou que ele representa como passadas". As imagens, as configurações e representações do tempo vivido ou imaginado, pertencem não somente ao campo da memória, mas também da História e da Historiografia, fato que, todavia é pouco exercitado em pesquisas, seja na (re)construção da própria história, do(s) lugar(es), dos espaço(s) e contexto(s).

Mas, afinal de contas, o que é a memória em pesquisa?

A memória pode ser considerada como uma trilha que o historiador/pesquisador pode transformar em fonte para sua pesquisa. Um fragmento que reluta ficar entre nós, que nos auxilia a criar elos, a estabelecer laços de identidade individual e coletiva. É por meio da recordação e da revivificação que muitas conexões são criadas no âmbito pessoal e coletivo. Ela se erige no embate entre os diversos campos do coletivo e do individual e na tensão entre passado, presente e futuro. Assim, a memória é constituída a partir dessa numerosa rede relacional. Segundo Todorov (2002), é primordial “compreender que memórias individuais e coletivas interagem para formar uma identidade memorial".

Segundo esse mesmo autor,

A recordação do passado é necessária para afirmar a própria identidade, tanto individual como de grupo. Um e outro também se definem, evidentemente, por sua vontade no presente e seus projetos de futuro; mas não podem prescindir dessa primeira lembrança (TODOROV, 2002, p. 199). 
Nesse sentido, é possível dizer que uma historiografia sobre a memória pode produzir outras memórias, silenciamentos e esquecimentos, e, por sua vez, memórias, silenciamentos e esquecimentos podem construir identidades coletivas e individuais. Com isso, admite-se que, a identidade é uma elaboração social em permanente construção, sendo um estado construído socialmente, que, "de certa maneira sempre acontece no quadro de uma relação dialógica com o outro" (CANDAU, 2011, p. 9). Nessa compreensão as memórias são um componente fundamental nesse processo, pois são importantes registros vividos (ou não) que partem das lembranças e eternizam lugares como referências e cenários para uma constante (re)visita ao passado. Nesse sentido reforça o mesmo autor, que "a memória nos dá esta ilusão: o que passou não está definitivamente inacessível, pois é possível fazê-lo reviver graças à lembrança" (CANDAU, 2011). Será por meio dessa(s) memória(s), que um individuo (ou o grupo) passa a se engajar em luta(s) para "imposição" de uma memória legitima através de um lugar de memória.

Com isso, pode se dizer que o lugar de memória é uma via de mão dupla, pois em certa medida atua como um componente contra o apagamento da memória quando serve de "fonte" de lembrança do passado e, em certa medida, é uma afirmação e legitimação de um determinado "regime de verdade" de um grupo sobre o passado. Assertiva que corrobora a constatação de Nora (1993) sobre o lugar de memória, quando diz que "são lugares, com efeito, nos três sentidos da palavra, material, simbólico, funcional [...]”. Assim, a (re)construção do passado é feita a partir de diferentes perspectivas e sempre orientadas por "batalhas" em que, se envolvem sujeitos ou grupos sociais no presente. É nessa necessidade de refazer um caminho, ou de encontrar uma lembrança, que a comunidade portuguesa satisfaz essa necessidade quando erige para si um lugar, na representação que produzem ao projetar a arquitetura da casa - um baluarte, que categoriza a comunidade portuguesa e seus sentidos.

Isso permite inferir que os membros da Casa de Portugal se apoiam na necessidade de apelo às lembranças, instituindo para si mesmos, uma memória de contestação para a justificação de uma identidade. Ou na acepção de Woodward (2014, p. 24), "necessitam evocar origens, mitologias e fronteiras do passado". Com essa memória de contestação e tentativa de legitimação de uma história para justificação de uma identidade, se verifica o que aponta Cabanha (2019), quando destaca que quando um sujeito ou grupo (re)visita o passado, “fala(m) sobre si e para si mesmo(s)". Assim, as histórias dos depoentes são relevantes, pois, convergem em torno da Casa de Portugal, que, a nosso ver, teve o propósito, ainda que 
inconsciente, de congregar os portugueses em torno de uma identidade nação. Constata-se que a presença portuguesa em Foz do Iguaçu se materializa a partir da década de 1950 (CABANHA, 2017). E, as memórias, relato dos depoentes apontavam essa imigração. Porém, não interessou saber se os discursos são "falsos ou verdadeiros", "reais ou ilusórios", mas sim, como funcionam e de que maneira estão articulados em torno de uma identidade portuguesa e do grupo de pertencimento.

\section{Recordações, narrativas e a escolha de Foz do Iguaçu}

Na data de 22 de julho de 1954, chega ao Brasil Manuel Alves Pereira Martins, um dos narradores dessa história, cujo desembarque acontece na cidade do Rio de Janeiro. Em sua trajetória rumo a Foz do Iguaçu foi guiado pela expectativa de uma melhor condição de vida para ele e sua família. Relata que estava ciente de que a construção da Ponte da Amizade, que liga o Brasil ao Paraguai, a partir do rio Paraná era uma obra que duraria certo tempo para ser concluída, pois iniciou em 1956 e concluída em 1965. Decidiu vir porque acreditava que seus filhos poderiam ter uma melhor condição de vida no futuro, além de poderem frequentar a escola. Como auxiliar de carpintaria, vislumbrou a possibilidade de trabalho nessa obra.

Logo no início da entrevista com Manuel, ele faz uma pausa e dirigi-se ao seu quarto, e, retornando à sala, onde conversávamos, ofereceu sua carteira de trabalho. Registra-se que esse gesto possui denso significado. Esse gesto faz inferir que sua intenção era uma forma de não se por à prova sua participação na construção da Ponte da Amizade, de modo que não pudesse duvidá-lo. Permite entender também que há outro fato implícito nesse gesto, a saber, o de que o trabalho para ele está intimamente ligado à sua identidade. Conforme seus relatos, tudo se iniciou quando muitos dos operários vieram com a empresa $\mathrm{SOTEG}^{4}$ para trabalharem na construção da Ponte da Amizade. Dentre eles, muitos acabaram ficando no município e, sendo em sua maioria portuguesa, se organizaram com o intuito de se congregarem.

Segundo ele, a maioria dos imigrantes portugueses radicados no Rio de Janeiro se inseriam em ofícios ligados à construção civil e, como a SOTEGE era de propriedade de um

\footnotetext{
4 “A Sociedade de Terraplepagem e Grandes Estruturas - SOTEGE foi fundada pelo engenheiro João Alfredo Castilho, fundador, primeiro presidente e proprietário do escritório no qual funcionava e até hoje funciona o SINICON. Castilho tinha forte ligação com Juscelino, o que o levou a, após construir a Ponte da Amizade entre o Brasil e o Paraguai no governo JK, erguer uma casa no Paraguai com o formato das iniciais do presidente e lhe dar de presente, em terreno doado pelo presidente Alfredo Stroessner" (CAMPOS, 2012, p. 83).
} 
cidadão português ${ }^{5}$, a empresa trouxe um grande fluxo de trabalhadores ${ }^{6}$ para atuarem diretamente na construção da Ponte da Amizade. Em seus relatos foi possível compreender a ênfase dada à participação do imigrante português na construção desse monumento e, acredita-se que ao fazer menção a essa parte da história, primeiramente como um imigrante e depois como um português, esse narrador busca deixar vestígios e afirmar seu grau de participação nessa história, a saber, na construção da história da cidade.

Em sua fala ele diz: "eu sou um dos pioneiros dessa cidade, quando cheguei aqui não tinha nada, era tudo mato” (MARTINS, 2016). Nela busca fixar raízes de pertencimento e de desejo e posse pela cidade. Indo de encontro a esse discurso, se observa que o mesmo é construído no sentido de manifestar seu espírito de desbravador, de pioneirismo na cidade, pois a todo o momento relatava que, no início, vivenciava uma condição extremamente difícil e de superação. Ao relatar que o "progresso não havia chegado por essas paragens", Manuel revela sua vontade de se inserir como pioneiro, como aquele desbravador forte e destemido.

A madeira bruta era serrada manualmente na serraria, "tudo era dificil, as moradias era tudo precária, de chão batido, era um sertão". Essas são as primeiras palavras ditas na primeira entrevista pelo senhor João da Silva Lavado (2016). Através dessas palavras, pode se inferir como era a vida na prática de alguns imigrantes que trabalhavam em lavouras ou madeireiras, e, dessa forma, compreender como era a rotina e o cotidiano de trabalho. Assim, observa-se que em alguns pontos os discursos - tanto memorial como alegórico - dos depoentes se concatenam em torno de um imaginário.

Nas palavras dele, a posse da terra no oeste paranaense estava baseada em conflitos e, assim, alguns imigrantes, buscavam alternativas para além do ramo da construção civil, principalmente, no trabalho como mascates viajantes ou se estabelecendo como proprietários de micro comércios. Em suas andanças e percorrendo o seu trajeto rumo ao oeste paranaense, ele relata que após chegar ao Brasil em 1952 - Porto de Santos, permaneceu por um dia na cidade, depois veio à cidade de São Paulo onde permaneceu poucas horas com destino ao norte paranaense, na cidade de Londrina, onde permaneceu trabalhando como auxiliar de serraria por sete meses. Recorda ele que

\footnotetext{
${ }^{5}$ João Alfredo Castilho, Engenheiro fundador, primeiro presidente e proprietário da Sociedade de Terraplanagem e Grandes Estruturas - SOTEGE. (CAMPOS, 2012, p. 83)

${ }^{6}$ Jornal Oeste em Revista - Traz a matéria enfatizando a vinda de 250 trabalhadores trazidos pela empresa SOTEGE, como enfatizado pelo senhor Manuel. Fonte: Disponível em: http://www.documentosrevelados.com.br/foz-do-iguacu/jk-prometeu-inaugurar-pone-da-amizade-ate-o-final-deseu-mandato/ (sem data de publicação). Acesso em: 21. Maio 2016.
} 
Como o serviço era muito pesado, e sem possibilidades de melhores condições, desci até cruzeiro do oeste, onde casei em 1953 com Manoela Lavado (portuguesa, filha de imigrantes) onde fiquei até 55, depois me mudei para Iporã ficando até 59, quando vim a Foz do Iguaçu (LAVADO, 2016).

A partir desses relatos, denota-se que há uma preocupação pela (re)construção em ressignificar acontecimentos e de sedimentar um lugar para eles, em primeiro lugar, e por conseguinte, para os personagens portugueses presentes na constituição de suas memórias em Foz do Iguaçu. Com isso se observa que as narrativas atuam no sentido de uma construção simbólica de uma identidade.

\section{Os caminhos para edificação e o(s) significado(s) da Casa de Portugal}

A fixação de um grupo de migrantes portugueses em Foz do Iguaçu, nas décadas de 1950 e 1960, também marca o início da construção de referências e significados a esse grupo. Umas das primeiras ações foi a celebração do Dia da Raça e de Camões ${ }^{7}$, que em Portugal se comemora na data de 10 de junho, que coincidentemente é à data em que se comemora o dia da fundação do município de Foz do Iguaçu. A esse respeito, ao narrar esse fato, o narrador diz o seguinte,

O pontapé inicial foi o dia da raça, eu sei que houve encontros um na casa do outro, jantares, almoços, conversamos muito pra isso... Mas era nesses eventos que a gente se reunia um grupo pequeno e que sentia que faltava fazer alguma coisa (LAVADO, 2016).

Segundo esse depoente, nesses eventos aproveitavam a oportunidade para se reunir, mas também eram oportunidades de discutir sobre a falta de organização coletiva. Como já tinham um terreno doado para a construção da associação por um português "abastado" e Faustino Ferreira Mendes - membro da comunidade, num gesto simbólico na data de 10 de junho de 1994 decidiram por iniciar a construção, que inicialmente se deu em um sistema de

\footnotetext{
7 “O Dia de Portugal, é originado de um culto cívico popular e nacional em torno do mito de Camões e das Comunidades Portuguesas. É comemorado no dia 10 de Junho cuja data assinala a morte de Luís Vaz de Camões. Como Camões foi uma figura emblemática, associada aos Descobrimentos, essa data (em que se cogita seja data natalícia de Camões) foi a escolhida como uma forma de o regime celebrar os territórios coloniais e o sentimento de pertença a uma grande nação espalhada pelo mundo, com uma raça e língua comum". Nesse sentido, o 10 de junho é sobretudo uma data simbólica” (MATTOSO, 2000, p. 305-306).
} 
cotas, em que todos os associados deveriam adquirir no mínimo uma a fim de custearem a construção.

A organização da "gente portuguesa" - como ele se refere - pode ser comprovada na existência desse movimento em prol de uma associação. A ata de fundação da associação, datada de 30 de dezembro de 1994 demonstra a congregação da primeira leva de imigrantes portugueses vindos a Foz do Iguaçu, em cuja reunião manifestaram o intento de reviver o legado da herança cultural dos antepassados,

Aos trinta dias do mês de dezembro de 1994, no salão social do Hotel Estoril, sito a Av, República Argentina, 694, nesta cidade de Foz do Iguaçu,PR, se reuniram pela primeira vez os senhores: Manuel Maria Lameiras, Faustino Ferreira Mendes, Hermínio Bento Vieira, João da Silva Lavado, Pestana da Silva Cortes, Manuel Marques de Matos, Antonio Avelino Teixeira, Fernando Rodrigues Valente, Célia Neto Pereira da Rosa, Silvio Manuel Neto Lameiras, Jaime Antonio da Costa Mendes, Miguel da Costa Mendes, Abílio Marques de Matos, José Bento Vieira, João Manuel Martins Lavado, João Manuel Alves Neto, no propósito de criar nesta cidade um "marco físico lusíada", que simbolizasse os costumes, as tradições a cultura Portuguesa e luso Brasileira. Todos os presentes foram unânimes da necessidade desse marco. Há mais de vinte anos que um grupo ou outro se reuniram nos dias mais históricos do nosso País, falando na criação de um clube, mas sempre acabou nas saudades da "Santa Terra" nosso propósito. A ideia maior é deixar para nossos descendentes um meio de não esquecerem suas origens, recordar os nossos antepassados que tanto contribuíram para o relacionamento entre os povos dos quatro cantos do mundo e divulgar nossa cultura; quem pode esquecer os grandes navegadores? Como o infante D. Henrique, Vasco da Gama, Fernão de Magalhães, Pedro Álvares Cabral, Diogo Cão e tantos outros de nossa história contemporânea" (PARANÁ, 2007, Fls. 55).

Aqui se percebe que o transcurso temporal não apagou ou silenciou as memórias que agrupam o sentimento de pertencimento da comunidade portuguesa em Foz do Iguaçu. As lembranças que eram acionadas em grupos familiares e de amigos nos dias festivos, em específico, no dia 10 de junho, encontram agora, depois de mais de duas décadas, ancoragem para materializar um marco de memória físico - a casa da Associação -, mas também simbólico, pois passa a permitir a celebração do ser português, por meio de eventos, músicas, gastronomia e a indumentária.

Denota que ao empreenderem um esforço associativo voltado para a preservação dos valores e ideários advindos das raízes culturais, de alguma forma contribuíram para o (re)ordenamento de uma memória e identidade coletiva. Também permite inferir que a ideia da associação tinha a missão de preservar os costumes, a língua, a culinária, os valores com o 
desiderato de estabelecer o "tipo português" numa sociedade que tal "jeito português" não era encontrado e ou não havia possibilidade desse achado, mesmo presente na cidade há décadas.

Essa obstinação em registrar esse momento "português" permite conjecturar que o fato de quererem fixar a coesão de uma identidade conferida pelo pertencimento, e para além disso, a busca da sedimentação dos laços de identificação com a Casa de Portugal se relaciona com as disputas de memória em uma cidade que preconiza a diversidade cultural. A associação viabiliza esse grupo materialmente e simbolicamente dentro deste contexto multicultural de Foz do Iguaçu. Portanto, esses marcos de memória, também exprimem fronteiras frente aos outros - argentinos, paraguaios -, bastante expressivos nesse espaço, à época.

Retomando os depoentes e suas narrativas, se observa o que as histórias têm em comum. Isso permite inferir e apreender os distintos significados que os indivíduos atribuem à identidade coletiva. As histórias por eles contadas sempre convergem para a Casa de Portugal, das quais é preciso falar brevemente. No tocante às Casas de Portugal construídas no Brasil, ou mais precisamente, "Associações de Beneficência Portuguesa" como eram costumeiramente chamadas, destaca-se que buscavam estabelecer redes de relações e de dependência entre a comunidade portuguesa. Nesse sentido, exemplifica-se com o chamamento e a conclamação dos imigrantes portugueses, inclusive, a consumirem produtos ali vendidos, como é o caso do anúncio publicado em junho de 1934, na Casa do Minho, que fora fundada no Rio de Janeiro quando a cidade ainda era capital da república, em cujos anúncios publicados se observam um forte apelo emotivo à identidade portuguesa. Diz a chamada:

Preferindo os produtos aqui anunciados, praticareis um acto de justiça, cumprireis um dever de gratidão, sereis bons portugueses e podeis, ao mesmo tempo, ter a certeza de auxiliar casa de indiscutível probidade e consumir bons produtos... Fazei propaganda das casas e produtos aqui anunciados (SCOTT, 2001, p. 20).

Esse chamamento à aquisição dos produtos ali vendidos, que necessariamente remetem à terra d'além mar, a exemplo do vinho, do pão e do azeite, não é o único ponto que se quer destacar, mas também, a dimensão simbólica desses discursos e da apresentação dessas casas como um lugar de memória, de ligação com a pátria. Com o intuito de auxiliar os imigrantes portugueses que procuravam auxílio nas obras assistenciais, é que em 14 de outubro de 1921, o Cônsul Geral de Portugal, Dr. Joaquim de Barros Ferreira da Silva 
discorreu sobre a necessidade de implantação de obras assistenciais destinadas aos compatriotas menos afortunados. Segundo ele a

Invasão diária do Consulado, por grande massa de portugueses, premidos pela sua angustiosa situação, solicitando proteção do seu cônsul, implorando trabalho, a alimentação, o regresso à terra querida e distante que haviam abandonado, mas que os receberia de braços abertos com caldo fumegante $\mathrm{e}$ consolador (SCOTT, 2001, p. 21)

Ainda nesse mesmo sentido, Scott (2001) aponta que,

Em São Paulo também são várias as instituições criadas por imigrantes portugueses para auxílio nos momentos de maior aflição. Talvez, um caso que possa ser considerado exemplar seja o da Real e Benemérita Sociedade Portuguesa de Beneficência de São Paulo que conta com quase um século e meio de existência. Criada em 1859 por iniciativa de 118 imigrantes portugueses, tinha o objetivo de atender seus associados e a comunidade portuguesa em geral. O prestígio da Instituição foi reconhecido, não só através da visita do Imperador D. Pedro II (1886), como através da concessão do título de Real e Benemérita, em 1911, concedido pelo Rei Carlos I de Portugal. Ainda hoje, é uma das mais conceituadas instituições beneficentes do país. Se as associações de beneficência e assistência proliferavam, este é um sinal inequívoco da vida dura e repleta de privações que enfrentava a maioria dos imigrantes portugueses. Contudo, este é apenas um indicador do malogro potencial a que muitos estavam sujeitos. Recuperar estas trajetórias que não deixaram marcas tão visíveis quanto os palacetes é um desafio para os investigadores. Trabalhos recentes têm vasculhado as mais variadas fontes para resgatar o percurso dos imigrantes menos afortunados (SCOTT, 2001, p. 22).

A questão do apelo aos homens de boa vontade, ao assistencialismo e à benemerência era direcionada ao socorro dos que procuravam aliviar suas necessidades e sofrimentos, ação esta, que vem de longa data e, assim, esse traço deveria marcar a presença portuguesa em solo estrangeiro, ou seja, esses "valores" deveriam estar imbricados na identidade do povo português. A respeito, corrobora Scott (2001) quando traz que

[...] não se diga que só os feitos de armas ou de conquistas lhe deram nome: Não! Temos também feitos de 'Religião e Caridade', que até hoje estão arraigados na alma deste Povo heróico, tanto que os espalham por toda a parte, sem olharem aos preconceitos de raça ou de nacionalidade. Onde está um Portuguez, está uma instituição de Caridade (SCOTT, 2001, p. 20).

Dessa forma, irmanados por esse apelo à benemerência e à dimensão simbólica do português, que a comunidade portuguesa radicada em Foz do Iguaçu buscou caminhos para a 
edificação da Associação Cultural Luso-Brasileira de Foz do Iguaçu. Mesmo que a organização local não alcançasse as dimensões das associações citadas anteriormente, assume um papel emblemático ao usar como argumento de criação, não esquecer suas origens e recordar os antepassados, conforme citado na Ata de Fundação da Associação.

\section{Disputas entre memórias: recordações, esquecimentos e enfrentamentos pela imposição de um "regime de verdade"}

Entre recordações e esquecimentos, uma pergunta que ficou sem resposta e, que não foi possível entender, foi o fato de como, e em que circunstância se deu a troca do nome da Associação pelo nome atual, Casa de Portugal. Esse fato é uma incógnita na pesquisa, pois, na tentativa de encontrar uma resposta, recorreu-se a alguns membros da comunidade portuguesa, mas não souberam (ou não quiseram) falar sobre o assunto. Nesse sentido, cabe pontuar o que afirma Caume (2003), quando diz que

O silêncio dos "dissidentes" tem razões complexas, onde o dizível e o indizível, o confessável e o inconfessável inserem-se nas redes de poder que atravessam aquele espaço social. Calar sobre o passado não significava necessariamente um ato falho ou um simples esquecimento: por um lado, cumpria a função de jogar à sombra acontecimentos que implicariam empecilhos, desconfortos nas possibilidades de convivência social no presente (CAUME, 2003, p. 148)

Nem mesmo os depoentes souberam dizer o motivo, nem mesmo o senhor João, que havia sido tesoureiro da entidade por vários anos, soube explicar. Mas, em uma entrevista, ele alega que "um dia chegou lá e o nome já estava posto" (LAVADO, 2016).

A esse respeito é necessário fazer um questionamento: Esse evento foi silenciado com o objetivo de não prejudicar a memória do grupo a fim de preservá-la de possíveis malentendidos ou conflitos?

Nesse sentido, a reflexão de Lopes (2007) é bem elucidativa, pois afirma que "a manipulação da memória por indivíduos ou grupos silencia lembranças proibidas, esconde conflitos e segredos guardados confidencialmente, a fim de que não prejudiquem a imagem que se quer perpetuar para o grupo" (LOPES, 2007, p. 179). Aqui vale lembrar também o que aponta Pollak (1989, p. 9), que diz que duas são as funções essenciais da memória, a saber, "manter a coesão interna e defender as fronteiras daquilo que o grupo tem como princípios comuns", o sujeito coletivo. 
Não se cogita aqui encontrar uma resposta definitiva para esse dilema, que, a nosso ver, permanece uma incógnita, visto que os silêncios têm seu significado. A hipótese que parece plausível é que o silêncio se deu justamente pelo fato de existir um processo judicial em andamento, que envolve a associação e alguns membros como litigantes. Cabe ressaltar que a intenção não é expor a nudez, as porfias e pelejas dentro da comunidade, mas é compreender como esse jogo de interesses afeta a memória e o campo do simbólico. É possível inferir que, nesse entrelaçamento entre silêncio e memória, como bem aponta Orlandi (1995, p. 59), o dizível e o indizível se mesclam, pois segundo essa autora, "a memória é feita de esquecimentos, de silêncios e silenciamentos".

Isso permite perceber que nessa organização em torno de uma "congregação" de vontades, existem infindáveis concessões e acordos que foram negociados pelos sujeitos. Nessa aventura pelos esteios para a Casa de Portugal, arquitetam o teor do Estatuto e da Ata de fundação, cujos documentos emblemáticos tinham por missão abrigarem os anseios da "raça", a saber, o Estatuto pregava o seguinte lema, "primordialmente, promover o intercâmbio luso-brasileiro e divulgação dos costumes, das tradições e da cultura da gente portuguesa e luso-brasileira" (PARANÁ, 2007, Fls. 60).

Em uma clara contraposição ao teor do Estatuto, ao se reunirem para a discussão da elaboração da ata de fundação, os sócios fundadores se encontram diante de um dilema, no qual contestam a forma de atuação de outro grupo de portugueses através da criação do Elos Clube - favorável a uma aproximação com a comunidade de não portugueses, conforme destaca-se a seguir,

A criação do Elos Clube em Foz do Iguaçu veio dividir mais a comunidade, em vez de unir. Em outras cidades o Elos Clube somou muito, em Foz do Iguaçu ele dividiu mais. O Elos Clube tem pontos em comum com os Centros ou Clubes Culturais Portugueses, mas ele procura expandir os costumes, tradições e cultura Brasileira; enquanto os Centros Culturais Portugueses procuram dar continuidade aos costumes, tradições e Culturas Portuguesas. A maneira como foi desenvolvido, e a falta de esclarecimento perante a Comunidade tem levado a confusões. Nos reunimos hoje no grande objetivo de fundar uma Associação Cultural Luso Brasileira e levar avante a construção deste Marco Lusíada, na cidade das Três Fronteiras; e assim dar continuidade aos costumes, tradições e Culturas Portuguesas e Luso Brasileira. Para que seja um ponto de apoio e de referência para todos nossos compatriotas que nos visitam (PARANÁ, 2007, Fls. 66).

Ao contestarem a legitimidade desse movimento, se comprova as disputas entre as memórias e os enfrentamentos pela imposição de um "regime de verdade", e, nesse sentido, a associação promove um debate favorável ao isolamento e distanciamento baseado na 
solidificação de uma "identidade" em seus associados, pois orienta seus associados a expandir os costumes, tradições e culturas portuguesas, ao mesmo tempo em que se colocam como "ponto de apoio e de referência" para todos os portugueses. Percebe-se assim, uma contradição quando se atenta para o teor do estatuto em suas finalidades primordiais e a ata de fundação da associação, ou seja, o aparelhamento discursivo da ata de fundação se põe numa linha de contraposição a uma assimilação, e dessa forma, (re)produz um ideário etnicista.

$\mathrm{Na}$ acentuação do dilema entre Elos Clube e Associação Cultural Luso-Brasileira se constata o que aponta Caume (2003), quando diz que, por vezes, uma memória

Apaga os vestígios pessoais e as marcas de uma trajetória que não se enquadra nas fronteiras delimitadas pelo aparato discursivo do Movimento; que obscurece os conflitos e as percepções divergentes; que sombreia os acontecimentos discordantes da linha narrativa linear construída e difundida pelo movimento (CAUME, 2003, p. 154).

Essas tensões internas dentro do grupo de portugueses é uma forma enfática de se vislumbrar como se dão as relações, as quais, nem sempre são homogêneas. Ao balizarem e delimitarem a história a um aparato discursivo em torno de uma identidade se compreende então a projeção da arquitetura da Casa de Portugal, que por si só, em sua forma, fala da presença de portugueses na cidade, pois remete ao perfil de uma antiga cidade medieval portuguesa, ficando evidente essa dimensão simbólica da casa, ou seja, criando a imagem de um lugar propício para o culto à memória, pois a casa denota a cultura como marca de valor a ser cultivada. Isso permite inferir que há uma apropriação simbólica do espaço por essa comunidade, pois (re)produzem, ao mesmo tempo, um lugar de memória e uma identidade.

Por sua vez, se percebe que na busca de uma aceitação, reconhecimento e legitimação de uma "identidade", os membros da comunidade portuguesa promovem uma exaltação à identidade portuguesa, e sendo assim, ao mesmo tempo promovem uma construção baseada na diferença. Todo esse simbolismo se observa também logo no início da construção da Casa de Portugal, quando esteve presente no ato simbólico de lançamento da pedra fundamental o senhor Pedro Ribeiro Meneses, embaixador de Portugal e a senhora Ana Paula Zacarias, cônsul de Portugal em Curitiba, além de outros membros da comunidade portuguesa em Foz do Iguaçu (PARANÁ, 2007, Fls. 78).

Assim, pode se dizer que todo esse simbolismo estava envolvido por uma difusão discursiva no sentido de exaltar a "gente portuguesa" e, dessa forma, promover determinados comportamentos e pensamentos. O que se supõe é que essa tarefa já não seria necessária ao 
terminarem a construção da "Casa", com a manifestação apenas de um membro do grupo em particular, visto que a partir de sua finalização como sede de um desiderato comunal, a associação passa a falar por si mesma, como uma fiel depositária da cultura portuguesa.

Como nos lembra o senhor João, "essa construção foi um trabalho árduo e demorado" (LAVADO, 2016). Uma das metas para a edificação da associação entre os membros da comunidade portuguesa era promover eventos culturais, para os quais eram convidados os associados, empresários, membros da comunidade e autoridades com o intuito de promover uma aproximação e, ao mesmo tempo, angariar fundos para custear a construção. Para isso, a associação e seus membros também se servem do pretexto de intercâmbio cultural, nos quais buscam propagar alguns valores com o objetivo de incentivar e fomentar a unidade, a fraternidade e a harmonia entre os portugueses residentes em Foz do Iguaçu e a comunidade iguaçuense, através da preservação do idioma, da cultura, dos costumes, de atividades culturais. A associação também denota necessidades de sedimentar uma afirmação política e de ligação junto à comunidade, como o exemplo da visita do prefeito municipal da cidade, à época, Celso Sâmis da Silva (PARANÁ, 2007, Fls. 80 e 81).

Ao concluírem a construção, para agregar os portugueses, a Associação passa a propagar um discurso de forte apelo que vincula a "Casa" a um lugar de memória. Nesse sentido, dotam a Associação com o conceito de lugar, conforme aponta Tuan (1983), quando diz que:

$\mathrm{O}$ espaço é mais abstrato do que lugar. O que começa como espaço indiferenciado transforma-se em lugar à medida que conhecemos melhor e o dotamos de valor [...], além disso, se pensarmos no espaço como algo que permite movimento, então lugar é pausa: cada pausa no movimento torna possível que a localização se transforme em lugar (TUAN, 1983, p. 6).

A (re)produção para dotar um sentido de valor à "Casa de Portugal”, se observa na apresentação musical feita pela turma de medicina da Faculdade do Porto durante sua vinda a Foz do Iguaçu, conforme figura 2, a seguir. 
Figura: 2: Vinda da turma de medicina da Faculdade do Porto - Intercâmbio cultural.

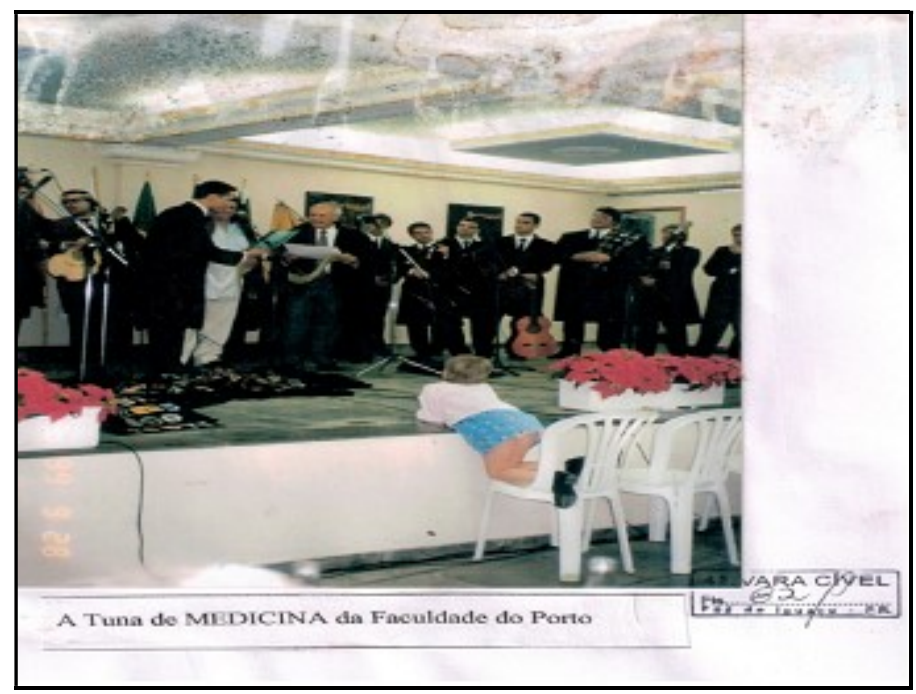

Fonte: (PARANÁ, 2007, Fls. 82.)

Diante dessa imagem é possível abstrair uma infindável variedade de simbolismos. Mas, a fim de explorar, vamos abstrair apenas a imagem da criança debruçada sobre o palco, com um olhar fixado diante da apresentação! Diante dessa imagem se vislumbra a criança que se deixa contagiar pela música.

Nessa "encenação", a música marca o passo e orienta as práticas e representações, e dessa forma, pode-se inferir que a música "funciona" como uma prece e um convite a uma assimilação da cultura portuguesa. Ampliando ainda mais essa visão observada pela criança, e de viajar pelos seus detalhes, pode-se dizer que os instrumentos musicais ali apresentados, as vestimentas, as canções e os discursos atuaram como uma "moldura" na criança, como num ritual, pois evocam as práticas dos antepassados, e dessa forma, passam uma mensagem de preservação de uma identidade.

Pode-se inferir que as práticas rituais e as diferentes formas de representação levadas a cabo pela associação, tanto as praticadas fora da Casa quanto as praticadas dentro da Casa, buscavam enfatizar a mensagem de uma coesão identitária na consciência do grupo. Nessa encenação, se observa um exemplo de atribuição de uma identidade para a criança, e, para os membros do grupo, de preservação.

Isso se observa nos relatos do senhor João, pois tal evento é umas das comemorações que costuma ser rememorada por ele, e constantemente, presente em sua lembrança e, dessa imagem de representação teatral, ele diz 
Nós tínhamos muitos eventos lá (na associação), teve um que foi muito bonito, a turma de medicina do Porto quando veio, foi um evento que mobilizou toda comunidade portuguesa em Foz, bem, pelo menos os que participavam da associação, pois muitos deixaram de ir com o tempo (LAVADO, 2016).

Essas festividades e montagens cênicas que marcam os eventos da comunidade portuguesa reproduzem um ambiente cultural e social, seja na Casa de Portugal ou os realizados na comunidade iguaçuense, e assim, verifica-se fortes indícios no sentido de autoidentificação junto à Casa de Portugal e de identificação com a luta para manterem vivas algumas memórias particulares e de seu grupo de pertencimento.

No tocante ao processo judicial, uma peça que se analisou mais detalhadamente foi o recurso ao tribunal, no qual se observa que tanto a associação, quanto o seu defensor selecionaram o que seria revelado, tanto o argumento jurídico como os documentos juntados aos autos, a exemplo do estatuto, das fotos e das atas. No entanto, sem adentrar a fundo na seara do direito, é necessário fazer um breve resumo sobre a questão judicial, pois ela serve de pano de fundo para o que denominamos de judicialização da memória.

O processo judicial de número 0016158.78.2007.8.16.0030, que envolve como partes a Associação Cultural Luso-Brasileira em Foz do Iguaçu como polo passivo e a Imobiliária Foz Nações Ltda. como polo ativo, foi ajuizada no ano de 2007, e versa sobre uma questão litigiosa com pedido de reintegração de posse, envolvendo certa "quantia" de terra do terreno onde a associação foi construída. Em primeira instância, a associação perdeu a causa e, dessa forma, recorreu ao Tribunal de Justiça do Estado Paraná com referência a essa sentença e, nesse recurso, foi vitoriosa.

O trecho que se destaca a seguir é esclarecedor. É uma parte do acórdão, cujo relator discorreu o seguinte:

Isso porque, restou indene de dúvidas que os apelantes exercem posse mansa e pacífica sobre o lote de terreno desde dezembro/1994, pelo menos, sem qualquer oposição firme de desalojamento deles, utilizando-se do imóvel com inegável ânimo de dono, e edificando no imóvel estabelecimento associativo de finalidade social e cultural, segundo exige o texto legal [...]. É de se anotar, desde logo, que o doador FAUSTINO FERREIRA MENDES, então conceituado empresário do ramo imobiliário, de nacionalidade portuguesa, mas radicado em Foz, resolveu juntamente com outros conterrâneos do além mar fundar a aludida sociedade lusitana, com vistas a manter vivas as tradições, os costumes e a cultura do povo português desterrado na tríplice fronteira, sendo certo que com esse desiderato ele e outros patrícios resolveram fazer por si mesmo, como mecenato, a sociedade em pauta como órgão de representação e orgulho de sua terra (PARANÁ, 2007, FLS 5-7). 
Não é a intenção adentrar no mérito da sentença aludida, mas sim, demonstrar que os conceitos de memória e identidade também estão imbricados nos discursos dos sujeitos que tocam o tema. Percebe-se que o magistrado levanta a questão cultural e a trata como um "bem” elevado. Esse discurso permite descortinar uma questão importante, pois denota o judiciário como uma instituição legitimadora que tem a última palavra sobre o assunto. Ampliando ainda essa visão, ao tempo em que a decisão é baseada quando toca a questão cultural e das tradições, o discurso do judiciário também atua como um formador de opinião e, dessa forma, ao dar ganho de causa à associação, o judiciário transforma a Casa de Portugal em "lugar de memória" à medida que a dota de valor.

Resolvida à disputa de memórias pela via judicial, se resolve um importante assunto para a comunidade portuguesa em Foz do Iguaçu, haja vista que o litígio envolvia muito mais que uma edificação ou uma porção de terra, pois a "Casa de Portugal" é a fiel depositária dos anseios e reminiscências históricas e culturais dos antepassados, tombada não oficialmente como patrimônio cultural por lei municipal, "mas, no imaginário", tombada como patrimônio cultural pela comunidade portuguesa.

\section{Considerações finais}

As análises possibilitaram constatar o passado, representado por meio das narrativas. Esse recorte de tempo permitiu compreender aspectos da Casa de Portugal como um lugar representativo da memória dos portugueses em Foz do Iguaçu. Isso permite afirmar que o espaço da Associação é um importante resultado de relações sociais de uma comunidade, de disputas, vinculadas às mais variadas forças: culturais, políticas, da representação do espaço vivido, entre outras. Dessas aproximações e distanciamentos, a Casa de Portugal se revela como uma marca na paisagem, como um testemunho que suscita recordações que são capazes de contar a história dessa comunidade.

Por meio das memórias, de apropriações e narrativas, a Casa de Portugal acumula ssentimentos e pertença, particulariza o espaço transformado em lugar, como uma tentativa de recuperação de uma memória, como um instrumento de afirmação da identidade portuguesa. É evidente que ao trabalhar, ainda que sucintamente com os relatos orais de dois depoentes, deixa-se de responder a inúmeras perguntas que o leitor porventura fará, porém, a pesquisa não teve por objetivo promover uma inquirição em busca de uma verdade histórica, 
e nesse ponto, acredita-se que este artigo e os discursos aqui apresentados fazem algumas concatenações, conectando a história do "homem comum" com a história da cidade.

Permitiu também, evidenciar que as narrativas produzidas, ainda que colocadas sucintamente neste artigo, dão um norte acerca da trajetória da comunidade portuguesa em torno a Casa de Portugal, lançando reflexões a partir e sobre as manifestações culturais que remetem ao imaginário e à construção de uma identidade portuguesa no município de Foz do Iguaçu.

\section{Referências}

BAUER, Babett. A caminho da "história das vivências"? História oral na Alemanha. In: Historiografia alemã pós-muro: experiências e perspectivas, In: GERTZ, René E; CORREA, Sílvio M. de S. (Orgs.) - Passo Fundo: Ed. Universidade de Passo Fundo; Santa Cruz do Sul: Ed.Universidade de Santa Cruz do Sul, 2007.

CABANHA, Samuel. Memórias que narram à cidade: a trajetória de dois imigrantes portugueses em Foz do Iguaçu. Dissertação de (Mestrado em Sociedade, Cultura e Fronteiras), Universidade Estadual do Oeste do Paraná, Centro de Educação, Letras e Saúde, Programa de Pós-graduação em Sociedade, Cultura e Fronteiras, 2017.

CABANHA, Samuel. O encontro entre história e memória: a materialização na forma de um memorial. Fronteiras: Revista de História. Dourados, MS. v. 21, nº 37. p. 173-192. Jan./ Jun. $2019 . \quad$ Disponível em: http://ojs.ufgd.edu.br/index.php/FRONTEIRAS/article/view/10141/5178. Acesso em: 25. Jul. 2019.

CAMPOS, Pedro Henrique Pedreira. A Ditadura dos Empreiteiros: as empresas nacionais de construção pesada, suas formas associativas e o Estado ditatorial brasileiro, 1964-1985. Tese (Doutorado em História Social), Universidade Federal Fluminense, Instituto de Ciências Humanas e Filosofia, Departamento de História, 2012.

CANDAU, J. Memória e identidade. São Paulo: Contexto, 2011.

CAUME, David José. Memórias da luta e lutas pela memória. História Oral, Volume 6, 2003, p. 133-158. Disponível em: http://revista.historiaoral.org.br/index.php?journal=rho\&page=issue\&op=view\&path $\% 5 \mathrm{~B} \% 5$ $\mathrm{D}=9 \&$ path $\% 5 \mathrm{~B} \% 5 \mathrm{D}=$ showToc. Acesso em: 26. Jun. 2019.

JORNAL OESTE EM REVISTA. JK prometeu inaugurar ponte da amizade ate o final de seu mandato. Disponível em: http://www.documentosrevelados.com.br/foz-do-iguacu/jkprometeu-inaugurar-pone-da-amizade-ate-o-final-de-seu-mandato/. Acesso em: 21. Maio 2016.

GINZBURG, Carlo. O queijo e os vermes: o cotidiano e as ideias de um moleiro perseguido pela inquisição. São Paulo: Companhia das Letras, 2006.

LAVADO, João da Silva. Entrevistas concedidas a Samuel Cabanha. Foz do Iguaçu, Julho de 2015 a Dezembro de 2016.

LE GOFF, Jacques. História e memória. Campinas, SP.Editora da UNICAMP, 2013. 
LOPES, Sônia Castro. Memórias em disputa: Anísio Teixeira e Lourenço Filho no Instituto de Educação do Rio de Janeiro (1932-1935). Revista Brasileira de História da Educação. N $^{\circ}$ 14 maio/ago. 2007. p. 177-201.

MARTINS, Manuel Alves Pereira. Entrevistas concedidas a Samuel Cabanha. Foz do Iguaçu, Abril de 2016 a Dezembro de 2016.

MATTOSO, José. História de Portugal. Bauru, SP : EDUSC; São Paulo, SP: UNESP; Portugal, PO: Instituto Camões, 2000.

NORA, Pierre. Entre memória e história: a problemática dos lugares. Projeto História: Revista do Programa de Estudos Pós-Graduados em História e do Departamento de História da PUC-SP. São Paulo, 10 de Dez. 1993. p. 7-28.

ORLANDI, Eni. P. As formas do silêncio - no movimento dos sentidos. Campinas, $3^{\mathrm{a}}$ Ed. da Unicamp, 1995.

PARANÁ, Poder Judiciário do Estado do. Processo Judicial número 0016158.78.2007.8.16.0030. Foz do Iguaçu, 2007.

POLLAK, Michael. Memória, esquecimento, silêncio. Estudos Históricos, Rio de Janeiro: CPDOC-FGV, v.2, n.3, 1989, p.3-15.

SCOTT, A. S. VOLPI. As duas faces da imigração portuguesa para o Brasil (décadas de 1820-1930). In: Congresso de História Econômica de Zaragoza, 2001, Zaragoza.

TODOROV, Tzvetan. Memoria del mal, tentación del bien - Indagación sobre el siglo XX. Barcelona: Ediciones Península, 2002.

TUAN, Yi-Fu. Espaço e Lugar: A Perspectiva da Experiência. São Paulo: Difel, 1983.

WOODWARD, Kathryn. Identidade e diferença: uma introdução teórica e conceitual. In: Identidade e diferença: a perspectiva dos estudos culturais. In: SILVA, Tomaz Tadeu (org). 15. Ed. - Petrópolis, RJ: Vozes, 2014. 